\title{
Vasopressin analogues and V1a receptor agonists in septic shock
}

\author{
Marc O. Maybauer • Dirk M. Maybauer
}

Published online: 11 February 2011

(C) Springer Basel AG 2011

\begin{abstract}
This article reviews the role of argininevasopressin and the vasopressin analogue terlipressin as potent alternative vasoconstrictors in the treatment of fluid and catecholamine-refractory septic shock. Terlipressin is the most selective, clinically available $\mathrm{V} 1$ receptor agonist, and may be more potent than arginine-vasopressin in restoring catecholamine refractory septic shock. Recent experimental and clinical studies on terlipressin, as well as the possible benefit of selective V1a receptor agonists, are discussed.
\end{abstract}

Keywords Hypotension - Microcirculation - Perfusion · Terlipressin · Vascular leakage

Hallmarks of severe sepsis and septic shock are generalized tissue malperfusion due to hypotension, and hyperpermeability secondary to microcirculatory/capillary leakage [1]. The recent Surviving Sepsis Campaign international guidelines for management of severe sepsis and septic shock suggest adequate fluid resuscitation, followed by norepinephrine or dopamine as first line vasopressors as a standard of care, and vasopressin as an alternative vasoactive drug, on organ and tissue perfusion/permeability in severe sepsis [2]. The rational for the use of vasopressin is

M. O. Maybauer $(\square) \cdot$ D. M. Maybauer

Division of Critical Care Medicine, Department of

Anesthesiology, University of Texas Medical Branch,

301 University Boulevard, Galveston, TX 77555-0591, USA

e-mail: momaybau@utmb.edu

M. O. Maybauer · D. M. Maybauer

Department of Anaesthesiology and Intensive Care Medicine,

Philipps University of Marburg, Baldinger Strasse 1,

35043 Marburg, Germany based on the findings of Landry et al. [3], who more than a decade ago documented that a deficiency in the plasma concentration of the vasopressor hormone arginine vasopressin (AVP) contributes to vasodilation in septic shock. It has been hypothesized that AVP administration may be useful as replacement hormone therapy for patients suffering septic shock [4]. Pilot studies involving the use of low-dose AVP infusion (0.01-0.04 U/min) in this patient population have shown that "add back" AVP therapy may reverse hypotension in catecholamine resistant shock states [5]. A recent large-scale multicenter study, the Vasopressin and Septic Shock Trial (VASST), suggested that add back AVP therapy (0.01-0.03 U/min) might reduce mortality in less severe septic shock [6]. However, an effective dose of AVP for patients with high severity of shock remains a vitally important issue in these patients because of the staggeringly high mortality rate. Most recently, Torgersen et al. [7] reported that in patients with severe septic shock a higher dose of AVP $(0.067 \mathrm{U} / \mathrm{min})$ than used in the VASST trial results in more effective restoration of cardiovascular function. The number of patients randomized into Torgersen's study is sufficient to provide useful additional hemodynamic information, though not sufficient to test for differences in survival outcome [8]. Randomized controlled trials that are adequately powered to test for survival differences in these severely ill patients are still warranted.

AVP, however, may not play the key role as hormone replacement or vasopressor therapy in the future. AVP is the endogenous ligand for the known subtypes of vasopressin receptors $\mathrm{V} 1 \mathrm{a}, \mathrm{V} 1 \mathrm{~b}(\mathrm{~V} 3)$, and $\mathrm{V} 2$, and could also act on the oxytocin receptor at high concentrations, with the V1a and V2 receptors being the principal subtypes mediating its physiological functions [9]. While the vasopressin V1a receptor mediates vasoconstriction [9], some of the V2 receptor mediated effects would be adverse in 
sepsis, such as hypercoagulation [10], antidiuresis [11], selective vasodilatation [12] as well as CNS changes [9]. This led to the general hypothesis that a selective V1a receptor agonist would be superior to the AVP in treating septic shock.

In this issue of Inflammation Research, Lange et al. [13] investigate the effects of two different dosing regimens of terlipressin on organ functions in ovine endotoxemia. The authors chose terlipressin because it is the most selective, clinically available V1 receptor agonist that has a higher selectivity for the V1 receptor than AVP (V1/V2 ratio 2.2 vs. 1), and may be more potent in restoring catecholamine refractory septic shock [14]. The major findings of the present study are that continuous low-dose versus bolus infusion of terlipressin was associated with improved surrogate parameters of myocardial contractility and renal function as well as less vascular leakage. It is important to point out that terlipressin has a prolonged effective half-life as compared to AVP (50 vs. $6 \mathrm{~min}$ ) and was traditionally used as splanchnic vasoconstrictor in hepatorenal syndrome and gastrointestinal bleeding in liver cirrhosis [14]. It may carry the risk of excessive systemic and/or microregional vasoconstriction after bolus injection. In a previous report of this group it has been demonstrated that overshooting increases in systemic and pulmonary vascular resistance and decreases in cardiac index noticed in sheep treated with bolus injections of terlipressin were prevented using the continuous infusion of the drug [15]. A clinical pilot study of terlipressin versus AVP infusion in septic shock (TERLIVAP) suggests that continuous low dose infusion of terlipressin $(1.3 \mathrm{mcg} / \mathrm{kg} / \mathrm{h})$ also reduced catecholamine requirements more effectively and was associated with less rebound hypotension than AVP $(0.03 \mathrm{U} / \mathrm{min})$. In this context, it can be speculated that less rebound hypotension is related to terlipressin's longer half life. However, this study provides useful preliminary hemodynamic data, but is limited by the number of patients in order to detect differences in survival outcome.

These experimental and clinical studies suggest that the more selective V1 receptor agonist terlipressin may be advantageous. However, high doses and bolus administration should be avoided given the potential risk of excessive vasoconstriction and decrease in cardiac index. Additional studies are needed to clarify the optimal time of therapy institution. At the present time, it has not been studied if early or late initiation of continous terlipressin administration is more beneficial. Furthermore, the efficacy and dose ranges of continuous infusion as far as the safety of this approach in comparison with other nonspecific vasopressinergic drugs, such as AVP is concerned, need to be elucidated. In addition, the effects of terlipressin on human microcirculation need to be studied in greater detail before a clinical use may be recommended, since only few human data of direct effects of terlipressin on microcirculatory perfusion are presently available. In comparative studies to other vasopressors in septic shock there was no difference between a bolus terlipressin or norepinephrine with respect to lactate levels and creatinine clearance [16]. Additional terlipressin to norepinephrine significantly improved renal function, but the mesenteric circulation was not evaluated and hepatic function was altered, and was accompanied by a rise in bilirubin and aminotransferases [17]. Terlipressin represents an effective pressor agent in patients with catecholamine-unresponsive septic shock. Whether or not terlipressin may improve the outcome of septic shock patients compared with standard therapy with catecholamines or AVP remains to be determined.

Given the results of recent experimental studies using highly selective V1a receptor agonists, reversing vascular leakage, massive fluid accumulation, and hypotension $[18,19]$, our point of view on AVP as replacement therapy in septic shock may change. Perhaps using AVP analogues with higher V1a receptor sensitivity such as terlipressin or a selective V1a receptor agonist instead of AVP, there may be a reduction in the mortality of these severely septic patients. At present, however, of all drugs that are clinically available, terlipressin is the one with the highest V1 receptor selectivity and should be further investigated in large randomized controlled trials to have better tools available to clinically fight septic shock.

Conflict of interest The authors declare to have no conflict of interest.

\section{References}

1. Farand P, Hamel M, Lauzier F, Plante GE, Lesur O. Review article: organ perfusion/permeability-related effects of norepinephrine and vasopressin in sepsis. Can J Anaesth. 2006;53:934-46.

2. Dellinger RP, Levy MM, Carlet JM, Bion J, Parker MM, Jaeschke R, et al. Surviving sepsis campaign: international guidelines for management of severe sepsis and septic shock. Crit Care Med. 2008;36:296-327.

3. Landry DW, Levin HR, Gallant EM, Ashton RC Jr, Seo S, D'Alessandro D, et al. Vasopressin deficiency contributes to the vasodilation of septic shock. Circulation. 1997;95:1122-5.

4. Landry DW, Oliver JA. The pathogenesis of vasodilatory shock. N Engl J Med. 2001;345:588-95.

5. Barrett LK, Singer M, Clapp LH. Vasopressin: mechanisms of action on the vasculature in health and in septic shock. Crit Care Med. 2007;35:33-40.

6. Russell JA, Walley KR, Singer J, Gordon AC, Hebert PC, Cooper DJ, et al. Vasopressin versus norepinephrine infusion in patients with septic shock. N Engl J Med. 2008;358:877-87.

7. Torgersen C, Dunser MW, Wenzel V, Jochberger S, Mayr V, Schmittinger CA, et al. Comparing two different arginine vasopressin doses in advanced vasodilatory shock: a randomized, controlled, open-label trial. Intensive Care Med. 2010;36:57-65.

8. Maybauer MO, Walley KR. Best vasopressor for advanced vasodilatory shock: should vasopressin be part of the mix? Intensive Care Med. 2010;36:1484-7. 
9. Maybauer MO, Maybauer DM, Enkhbaatar P, Traber DL. Physiology of the vasopressin receptors. Best Pract Res Clin Anaesthesiol. 2008;22:253-63.

10. Doepker BA, Lucarelli MR, Lehman A, Shirk MB. Thromboembolic events during continuous vasopressin infusions: a retrospective evaluation. Ann Pharmacother. 2007;41:1383-9.

11. Dibas AI, Mia AJ, Yorio T. Aquaporins (water channels): role in vasopressin-activated water transport. Proc Soc Exp Biol Med. 1998;219:183-99.

12. Aki Y, Tamaki $\mathrm{T}$, Kiyomoto $\mathrm{H}$, He H, Yoshida $\mathrm{H}$, Iwao $\mathrm{H}$, et al. Nitric oxide may participate in $\mathrm{V} 2$ vasopressin-receptormediated renal vasodilation. J Cardiovasc Pharmacol. 1994;23: $331-6$.

13. Lange M EC, Rehberg S, Morelli A, Köhler G, Kampmeier TG, Van Aken H, Westphal M. Effects of two different dosing regimens of terlipressin on organ functions in ovine endotoxemia. Inflamm Res. 2011 (in press).
14. Pesaturo AB, Jennings HR, Voils SA. Terlipressin: vasopressin analog and novel drug for septic shock. Ann Pharmacother. 2006;40:2170-7.

15. Lange M, Morelli A, Ertmer C, Koehler G, Broking K, Hucklenbruch $\mathrm{C}$, et al. Continuous versus bolus infusion of terlipressin in ovine endotoxemia. Shock. 2007;28:623-9.

16. Albanese J, Leone M, Delmas A, Martin C. Terlipressin or norepinephrine in hyperdynamic septic shock: a prospective, randomized study. Crit Care Med. 2005;33:1897-902.

17. Leone M, Albanese J, Delmas A, Chaabane W, Garnier F, Martin C. Terlipressin in catecholamine-resistant septic shock patients. Shock. 2004;22:314-9.

18. Traber D. Selective V1a receptor agonists in experimental septic shock. Crit Care. 2007;11:P51.

19. Rehberg S, Ertmer C, Vincent JL, Morelli A, Schneider M, Lange $\mathrm{M}$, et al. Role of selective V1a receptor agonism in ovine septic shock. Crit Care Med. 2010 (epub ahead of print). 